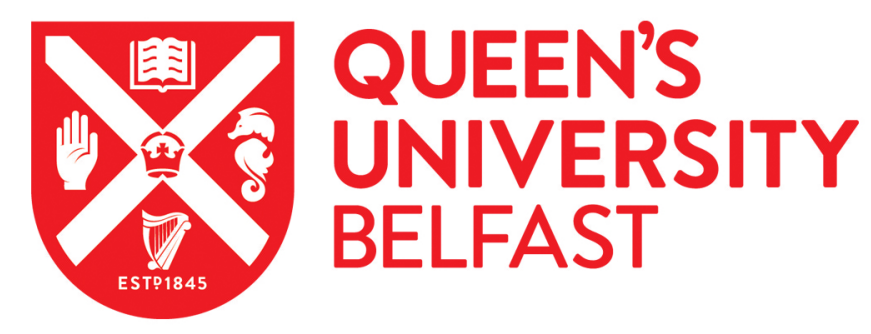

\title{
The use of a novel compact fluorosensor for in situ monitoring of the photocatalytic destruction of methylene blue dye effluents
}

Robertson, P. K. J., Lee, S. K., McStay, D., \& Pollard, P. M. (2012). The use of a novel compact fluorosensor for in situ monitoring of the photocatalytic destruction of methylene blue dye effluents. SENSORS AND ACTUATORS B-CHEMICAL, 168, 118-122. https://doi.org/10.1016/j.snb.2012.03.061

Published in:

SENSORS AND ACTUATORS B-CHEMICAL

Document Version:

Peer reviewed version

Queen's University Belfast - Research Portal:

Link to publication record in Queen's University Belfast Research Portal

Publisher rights

○ 2012 Elsevier B.V. All rights reserved.

\section{General rights}

Copyright for the publications made accessible via the Queen's University Belfast Research Portal is retained by the author(s) and / or other copyright owners and it is a condition of accessing these publications that users recognise and abide by the legal requirements associated with these rights.

Take down policy

The Research Portal is Queen's institutional repository that provides access to Queen's research output. Every effort has been made to ensure that content in the Research Portal does not infringe any person's rights, or applicable UK laws. If you discover content in the Research Portal that you believe breaches copyright or violates any law, please contact openaccess@qub.ac.uk. 
The use of a novel compact fluorosensor for in-situ monitoring of the photocatalytic destruction of methylene blue dye effluents.

Peter K.J. Robertson ${ }^{a^{*}}$, Soo-Keun Lee ${ }^{\mathrm{b}}$, Daniel McStay ${ }^{\mathrm{c}}$ and Patricia M. Pollard ${ }^{\mathrm{a}}$

aIDeaS, Innovation, Design and Sustainability Research Institute, Robert Gordon University, Schoolhill, Aberdeen, AB10 1FR, UK

bDaegu Gyeongbuk Institute of Science and Technology, Division of Nano \& Bio Technology, $5^{\text {th }}$ Floor, Daegu Techno-park, Venture 2, 711 Hosan-dong, Dalseogu, Daegu, 704-230, Korea, 'MCSC, 6 Kirkton of Durris, Banchory, Aberdeenshire, AB31 6BQ

* Corresponding Author phone: +44 1224 263750; fax: +44 1224 262759; e-mail: peter.robertson@rgu.ac.uk 


\begin{abstract}
The use of $\mathrm{TiO}_{2}$ photocatalysis for the destruction of dyes such as methylene blue has been extensively reported. One of the challenges faced in both the laboratory and large scale water treatment plants is the fact that the samples have to be removed from the reactor vessel and the catalyst separated prior to analysis being undertaken. In this paper we report the development of a simple fluorimeter instrument and its use in monitoring the photocatalytic destruction of methylene blue dyes in the presence of catalyst suspensions. The results reported show that the instrument provides an effective method for in-situ monitoring of the photocatalytic destruction of fluorescent dyes hence allowing more accurate measurement due to the minimisation of sample loss and cross contamination. Furthermore it also provides a method for real time monitoring of the dye pollutant destruction in large scale photocatalytic reactors.
\end{abstract}

\title{
Keywords
}

Photocatalyst, in-situ fluorosensor, $\mathrm{TiO}_{2}$, methylene blue, dye, kinetic isotope effect 


\section{Introduction}

The use of semiconductor photocatalysis for treatment of waste and potable waters has been a topic of intense research activity over the past 25 years [1-4]. One challenge in the application of this technique is the requirement for an in-situ sensing method for monitoring removal of pollutants from the water, particularly in larger water treatment units. There are several analytical methods that have been used for monitoring pollutant destruction, including chromatography, spectroscopy, and electroanalytical techniques [5-7]. In many water treatment

applications, the $\mathrm{TiO}_{2}$ photocatalyst is deployed as powder dispersions in the contaminated water [1-4] and prior to analysis the water must be sampled and the catalyst separated from the water specimen. Both these steps can be time consuming and also present challenges for precise analysis due to risk of sample loss and contamination. It would therefore be highly desirable to analyse the destruction of pollutants in situ without sample pre-treatment.

Dyes pose a potential environmental hazard because they produce and involve a variety of organic chemicals in their manufacturing processes. Some attempts therefore have been made to study the photocatalytic destruction of several dyes for example rhodamine B [8], eosin [9], methylene blue[10-12] and azo dyes such as acid red 14, acid orange 8 and acid orange 7 [13-15].

Fluorescence spectroscopy has proven to be a versatile tool for numerous applications particularly monitoring of fluorescent contaminants such as dyes in 
water. Fluorescence spectroscopy has three major advantages over other lightbased investigation methods, these are high sensitivity, high speed, and because light is emitted in all directions, the geometry of detection is much more flexible $[6,8]$. Sensitivity is an important issue because the fluorescence signal is proportional to the concentration of the substance being investigated. Relatively small changes in ion concentration in living cells can have significant physiological effects. While absorbance measurements can only reliably determine concentrations as low as tenths of a micro molar, fluorescence techniques can accurately measure concentrations at one million times smaller i.e. pico and even femto molar levels. Using fluorescence, one can also monitor very rapid changes in concentration, with changes in fluorescence intensity in the order of picoseconds being detectable if necessary. Since it is a non-invasive technique, fluorescence does not interfere with a sample. Samples are not affected or destroyed in the process, and no hazardous by-products are generated. The excitation light levels required to generate a fluorescence signal are low, reducing the effects of photo-bleaching, and therefore living tissue can be investigated with no adverse effects on its natural physiological behaviour. Furthermore, with regards to photocatalysis, the fluorescent signal is less affected by scattered light caused by $\mathrm{TiO}_{2}$ particles compared to a UV-Visible spectrum signal because the fluorescent signal is collected from a different wavelength to the excitation wavelength. 
This paper reports the direct detection of the photocatalytic destruction of methylene blue in water using a novel compact fluorimeter that can measure fluorescence signal and hence concentration, through a glass vessel and does not require sample removal from reactor vessels or sample preparation prior to analysis.

\section{Materials and Methods}

\subsection{Materials}

$\mathrm{TiO}_{2}$ (P25, Degussa, UK), Methylene Blue (Aldrich Chemicals) and heavy water (Aldrich chemicals) were used as received.

\subsection{Photocatalysis}

Photocatalysis experiments were conducted in a poly-methylmethacrylate (PMMA) fluorescence cell and the $\mathrm{TiO}_{2}$ powder was agitated using a magnetic stirrer. Samples were irradiated using a $150 \mathrm{~W}$ medium pressure mercury lamp (Spectral output 250-550 nm, Oriel). Aqueous solutions of methylene blue (10-5$\left.10^{-4} \mathrm{M}\right)$ were illuminated in the presence of air and the photocatalyst $(0.1 \% \mathrm{~m} / \mathrm{v}$ slurry of $\mathrm{TiO}_{2}$ ). The same procedure was adopted for the experiments performed in $\mathrm{D}_{2} \mathrm{O}$.

\subsection{Analysis}


The destruction of the methylene blue dye was monitored using a Perkin Elmer fluorescence spectrometer (LS 50B) and a novel compact fluorimeter developed and constructed in-house.

A schematic diagram of the new compact fluorosensor is shown in Fig. 1. This instrument consisted of a blue light emitting diode (light source) emitting at a peak wavelength of $470 \mathrm{~nm}$, photodetector lenses to focus the beam, filters and a dichroic mirror. The lens and filters collect the emitted fluorescent light from the analyte under examination. Blue (470/IL/25), red (620/IL/25) and green (520/IL/25) interference filters were all supplied by Comar Optics. The aspheric lenses (10/AF/25) were also supplied by Comar optics. The entire instrument was encapsulated in a housing of dimensions $25 \mathrm{~cm} \times 10 \mathrm{~cm} \times 8 \mathrm{~cm}$.

Operating conditions of the Perkin Elmer fluorescence spectrometer (LS 50B) are summarised in Table 1. The fluorescence is recorded as arbitrary units. A standard solution is measured each run to ensure comparability between the fluorescence measurements. The scale can be altered by 3 factors of 10 using the 3 gain selection settings.

\section{Results and discussion}

\subsection{Comparison between bench fluorimeter and compact fluorimeter}

The fluorescence of a methylene blue solution was measured using a bench fluorescence spectrometer (Perkin-Elmer) and the new compact fluorimeter for 
the comparison of both instruments. The fluorescence intensities were plotted against varying concentrations of methylene blue dye.

As shown in Fig. 2, both the bench fluorimeter and the compact fluorimeter showed a good linear relationship between the intensity and concentration up to $4.16 \times 10^{-5} \mathrm{M}$. Although the bench fluorimeter showed marginally higher sensitivity, the compact fluorimeter displayed slightly better linearity.

In order to investigate the effects of $\mathrm{TiO}_{2}$ particles on the fluorescence of methylene blue, a $0.05 \%(\mathrm{w} / \mathrm{v})$ suspension of $\mathrm{TiO}_{2}$ in a methylene blue solution, was measured. The fluorescence intensities of the varying concentrations of methylene blue solutions in the presence of the $\mathrm{TiO}_{2}$ powder dispersions are displayed in Fig. 3. From the figure it can be seen that the calibration plot of methylene blue, which was measured by the bench fluorimeter was not linear when fluorescence was measured in the presence of the $\mathrm{TiO}_{2}$ powder suspensions. The compact fluorimeter, however, displayed a linear relationship at concentrations of methylene blue up to $2.84 \times 10^{-5} \mathrm{M}$.

In order to investigate the effect of the $\mathrm{TiO}_{2}$ powder on the response of both instruments the fluorescence signal was measured under different concentrations of photocatalyst powder (Fig 4). In the case of the standard bench fluorimeter, the fluorescence intensities displayed a very sensitive but short linear range up to a loading of $0.025 \%(w / v) \mathrm{TiO}_{2}$. With the compact fluorimeter, however, a very 
long linear range was observed as displayed in the figure. The anomalies between these results were believed to be due to the differences in the optical geometries of the bench fluorimeter and the compact fluorimeter.

A typical standard bench top fluorimeter consists of a light source, detector, several lenses, gratings and the sample cell (Fig 1b). This optical geometry is very sensitive to the sample cell position. Therefore, small changes in path length and position can strongly affect the observed fluorescence signal. Furthermore, there is a risk of scattering light passing through the grating components, which also may affect the fluorescence signal. With the compact fluorosensor instrument, however, there was no chance of interference of the fluorescence signal from scattered light caused by the $\mathrm{TiO}_{2}$ dispersion because all interfering light has been cut off by the filter in front of the photodiode with the exception of the fluorescent light emitted from the dye molecule. Furthermore, this system was designed to minimise sample position dependence by applying beam dispersion.

Overall, the results indicated that the compact fluorimeter appeared to be a suitable system for direct detection of dye destruction with a $\mathrm{TiO}_{2}$ dispersed powder photocatalysis system. Consequently this system was used for direct monitoring for destruction of methylene blue dye. 


\subsection{Direct detection of the destruction of dyes using the compact fluorimeter}

Before monitoring the photocatalytic destruction of methylene blue, the change in dye fluorescence under UV irradiation was monitored. This was specifically to determine if there was any direct photolytic degradation of the dye in the absence of the photocatalyst and also to ensure that a stable signal was obtained from the fluorosensor. No evidence of direct dye photolysis was observed after 60 minutes irradiation.

The photocatalytic destruction of methylene blue was then examined at different initial concentrations using the compact fluorimeter to monitor the dye degradation process (Fig 5). In each case a complete destruction of the dye had been achieved with 30 minutes photocatalysis. The spike peaks observed in Fig 6 were typical of noise generated from the UV lamp power source. Typically for photocatalytic decomposition processes, higher initial concentrations resulted in faster initial destruction rates.

To demonstrate the repeatability of photocatalytic activity of the $\mathrm{TiO}_{2}$ material, continuous destruction cycles of methylene blue were performed for six continuous destruction cycles (Fig. 6). Initially a $0.05 \%$ (w/v) $\mathrm{P}_{2} 5 \mathrm{TiO}_{2}$ was dispersed in $4 \mathrm{ml}$ of methylene blue $\left(2.27 \times 10^{-5} \mathrm{M}\right)$ sample solutions. After the destruction of the dye, $0.4 \mathrm{ml}$ of solution was replaced by a concentrated 
methylene blue solution, maintaining an initial concentration of $2.27 \times 10^{-5} \mathrm{M}$. One issue with this approach was that some of the photocatalyst material was removed in each of the recycling steps. On the second cycle, a sample was injected while the UV lamp was turned on, therefore a marginally lower fluorescence signal was observed at the initial destruction time. The overall destruction time of the dye was reduced in the repeated destruction cycles. This may have been due to the reduced level of photocatalyst in the reactor vessel or a marginal reduction in photocatalytic activity of $\mathrm{TiO}_{2}$ in the subsequent cycles.

\subsection{Kinetic solvent isotope effect in photocatalytic destruction of methylene blue}

The kinetic solvent isotope effect on the photocatalytic destruction of methylene blue was also assessed. This technique can provide information on the basic processes involved in the photocatalytic reaction with the methylene blue. From Table 2 it can be seen that the initial rate of methylene blue destruction in the $\mathrm{D}_{2} \mathrm{O}$ solvent was 5 times slower than that observed in water. Cunningham and Srijarani [16] and Robertson et al. [17] reported a similar kinetic isotope effect for the destruction of isopropanol and microcystin-LR respectively using $\mathrm{TiO}_{2}$ photocatalysts. It was proposed that the slower destruction rate was due to lower quantum efficiency for the formation of $\mathrm{OD}^{*}$ radicals on the $\mathrm{TiO}_{2}$ surface which was believed to be the main oxidant in the photocatalytic destruction of the organic compounds. As a result there was a lower concentration of $\mathrm{OD}^{*}$ available in solution for oxidation of the methylene blue than there would be of 
$\mathrm{OH}^{*}$. The results obtained in this study would appear to indicate that the photocatalytic destruction of methylene blue appears to follow a similar pathway to both isopropanol and microcystin-LR as the same level of kinetic solvent isotope effect was observed. This process is likely to be via the surface formation of hydroxyl species which is likely to be the primary agent in dye degradation. Salvador has, however, reported that reactive holes have been involved in photocatalytic decomposition reactions in aqueous suspensions of $\mathrm{TiO}_{2}$ as an alternative mechanism to hydroxyl radical attack [18]. Whatever mechanism applies the compact instrument is particularly useful for this type of analysis where there may be subtle changes in destruction rates, hence providing a more accurate measurement of the precise level of kinetic solvent isotope effect. Analytical methods which require catalyst separation and pre-treatment are prone to both sample loss and potential contamination which may reduce the accuracy of the analysis.

\section{Conclusions}

Compared to the compact instrument, the standard bench fluorimeter displayed a narrower linear range to the fluorescence signal of dyes and was subject to significant interference from $\mathrm{TiO}_{2}$ dispersions. Therefore the bench instrument would not be applicable for direct monitoring of photocatalytic destruction in a $\mathrm{TiO}_{2}$ dispersed system. The compact fluorimeter, however, showed an excellent linear relationship. 
Using the compact fluorimeter, the destruction of dyes was directly monitored with no sample pre-treatment. This system also has the potential to provide a standard test method for comparing photocatalytic activity of different $\mathrm{TiO}_{2}$ materials for the destruction of fluorescent dye compounds. A similar kinetic solvent isotope effect was observed for the photocatalytic destruction of methylene blue to that reported by other groups for different molecules.

Overall the compact fluorimeter has displayed excellent potential for direct kinetic monitoring of photocatalytic destruction of dyes. It is important when performing work of this nature to ensure that as many variables as possible are kept constant between the different systems. The disadvantage with traditional analytical methods is that there is a risk of sample loss or contamination when withdrawing samples for analysis. Consequently what may appear to be a reduction in rate between the specimens may be due to sample loss rather than a kinetic effect or reduction in catalyst efficiency. The compact instrument avoids this problem since the analytical process is non-invasive.

Additionally, this novel instrument has significant advantages in real time detection, since no sample treatment is necessary and the instrument is relatively cheap to produce.

\section{References}


[1]. M. R. Hoffmann, S. T. Martin, W. Choi, D. W. Bahnemann, Environmental applications of semiconductor photocatalysis, Chem. Rev. 95 (1995) 69-96.

[2]. A. Mills, S. L. Hunte, An overview of semiconductor photocatalysis, J. Photoc. Photobio. A 108 (1997) 1-35.

[3]. Cathy McCullagh, Jeanette M C Robertson, Detlef W. Bahnemann and Peter K. J. Robertson, The Application of $\mathrm{TiO}_{2}$ Photocatalysis for Disinfection of Water Contaminated with Pathogenic Micro-organisms.- A Review, Research on Chemical Intermediates, 33 (2007) 359-375.

[4]. Peter K.J. Robertson, Detlef W. Bahnemann, Jeanette M. C. Robertson, and Fiona Wood. Photocatalytic Detoxification of Water and Air", in "Environmental Photochemistry Part II, eds. Pierre Boule, Detlef W. Bahnemann and Peter K.J Robertson, Springer-Verlag Berlin Heidelberg. 2005, pp 367-424.

[5]. F.W. Fifield and P.J. Haines (Eds). Environmental analytical chemistry, $2^{\text {nd }}$ Edition, Wiley-Blackwell, 2000, 978-0-632-05383.

[6]. P. Pollard, P.K.J. Robertson, K. Christidis, M. Adams, S. Officer, G.R. Prabhu, K. Gow and A. Morrisson. "Environmental Forensic Investigations: The Potential Use of a Novel Heavy Metal Sensor and Novel Taggants" in "Criminal and Environmental Soil Forensics" edited by Karl Ritz, Lorna Dawson and David Miller, Springer Netherlands, 2009, 477-490,

[7]. D. McStay, P.K.J. Robertson, P. Pollard, I. Edwards, E. Bonsen, A. Al-Obaidi, and D. Tait, A multicapability sensor for hydrocarbons, synthetic based fluids and heavy metals: Applications for environmental monitoring during removal of drill cutting piles, Underwater Technology, 2002, 25, 69-75. 
[8]. Y. Ma, J Yao, J., Photodegradation of rhodamine B catalyzed by $\mathrm{TiO}_{2}$ thin film, J. Photoc. Photobio. A 116 (1998) 167-170.

[9]. F. Zhang, J. Zhao, T. Shen, H. Hidaka, E. Pelizzetti, N. Serpone, TiO $2-$ assisted photodegradation of dye pollutants II. Adsorption and degradation kinetics of eosin in $\mathrm{TiO}_{2}$ dispersions under visible irradiation, Appl. Catal. BEnviron. 15 (1998) 147-156.

[10]. S. Lakshimi, R. Renganathan, S. Fujita, Study on $\mathrm{TiO}_{2}$-mediated photocatalytic degradation of methylene blue, J. Photoc. Photobio. A 88 (1995) 163-167.

[11]. A. Mills, J. Wang, Photobleaching of methylene blue sensitised by $\mathrm{TiO}_{2}$ : an ambiguous system?, J. Photoc. Photobio. A 127 (1999) 123-134.

[12]. A. Houas, H. Lachheb, M. Ksibi, E. Elaloui, C. Guillard, J-M.Herrmann, Photocatalytic degradation pathway of methylene blue in water, Appl. Catal. B-Environ. 31 (2001) 145-157.

[13]. N. Daneshvar, D. Salari, A. R. Khataee, Photocatalytic degradation of azo dye acid red 14 in water: investigation of the effect of operational parameters, J. Photoc. Photobio. A 157 (2003) 111-116.

[14]. M. Sapquib, M. Muneer, Titanium dioxide mediated photocatalyzed degradation of a textile dye derivative, acid orange 8 , in aqueous suspensions, Desalination 155 (2003) 255-263.

[15]. M. Stylidi, D. I. Konarides, X. E. Verykios, Visible light-induced photocatalytic degradation of Acid Orange 7 in aqueous $\mathrm{TiO}_{2}$ suspensions, Appl. Catal. B-Environ. 47 (2004) 189-201. 
[16]. J. Cunningham, S. Srijaranai, Isotope-effect evidence for hydroxyl radical involvement in alcohol photo-oxidation sensitized by $\mathrm{TiO}_{2}$ in aqueous suspension, J. Photoc. Photobio. A 43 (1988) 329-335.

[17]. P. K. J. Robertson, L. A. Lawton, B. J. P. A. Cornish and M. Jaspars. Processes Influencing the Destruction of Microcystin-LR by $\mathrm{TiO}_{2}$ Photocatalysis. J. Photoc. Photobio. A. 116 (1998) 215-219.

[18]. P. Salvador, On the nature of photogenerated radical species active in the oxidative degradation of dissolved pollutants with $\mathrm{TiO}_{2}$ aqueous suspensions: A revision in the light of the electronic structure of adsorbed water. J. Phys. Chem. C, 111 (2007) 17038-17043. 


\section{Captions for Figures and Tables}

Table 1. Fluorescence spectroscopy operating conditions using bench top fluorescence spectrometer.

Table 2. Isotope effect based on rate of photocatalytic destruction of methylene blue.

Figure 1. a) Schematic diagram of compact fluorimeter. b) Schematic diagram of standard bench fluorimeter.

Figure 2. Calibration curves of methylene blue.

Figure 3. Calibration curves of methylene blue in $0.05 \%$ (w/v) $\mathrm{P}_{25} \mathrm{TiO}_{2}$ solution.

Figure 4. Fluorescence signals obtained with varying concentrations of P25 $\mathrm{TiO}_{2}$.

Figure 5. Typical destruction curves of methylene blue (0.05 \% (w/v) P25 $\mathrm{TiO}_{2}$ ). Moving from x-axis $7 \times 10^{-6} \mathrm{M}, 1.4 \times 10^{-5} \mathrm{M}, 2.1 \times 10^{-5} \mathrm{M}, 2.8 \times 10^{-5} \mathrm{M}, 5.7$ $\times 10^{-5} \mathrm{M}$ and $8.5 \times 10^{-5} \mathrm{M}$ methylene blue.

Figure 6. Continuous destruction cycles $\left(2.27 \times 10^{-5} \mathrm{M}\right.$ methylene blue, 0.050 , $0.045,0.041,0.036,0.033,0.030 \%(w / v) \mathrm{P}^{2} 5 \mathrm{TiO}_{2}$ (from left to right)). 
Figures and Tables.

Table 1.

\begin{tabular}{lc}
\hline Parameter & Setting \\
\hline Excitation wavelength & $470 \mathrm{~nm}$ \\
\hline Emission collected & $680 \mathrm{~nm}$ \\
\hline Slit width & $5 \mathrm{~nm}$ \\
\hline Scan speed & $1000 \mathrm{~nm} / \mathrm{min}$ \\
\hline
\end{tabular}

Table 2

\begin{tabular}{llll}
\hline Substrate & Solvent & Initial rate $(\mu \mathrm{M} / \mathrm{min})$ & Relative rate \\
\hline Methylene blue & & & 1 \\
& $\mathrm{H}_{2} \mathrm{O}$ & 7.8 & 0.19 \\
\cline { 2 - 4 } & & 1.5 & \\
\hline
\end{tabular}




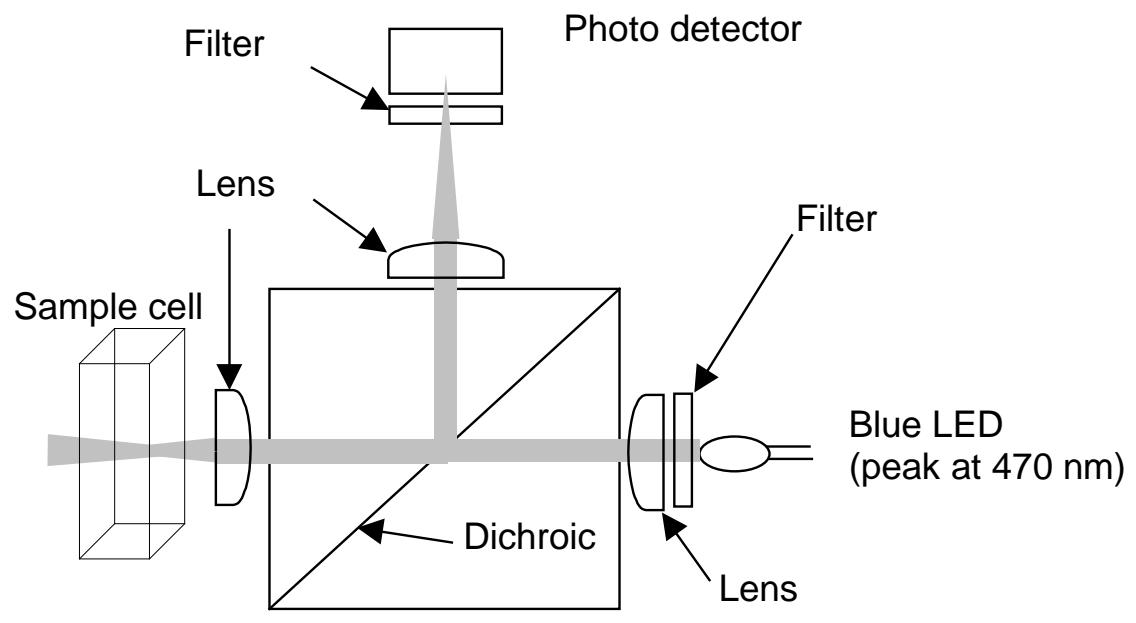

Figure 1a)

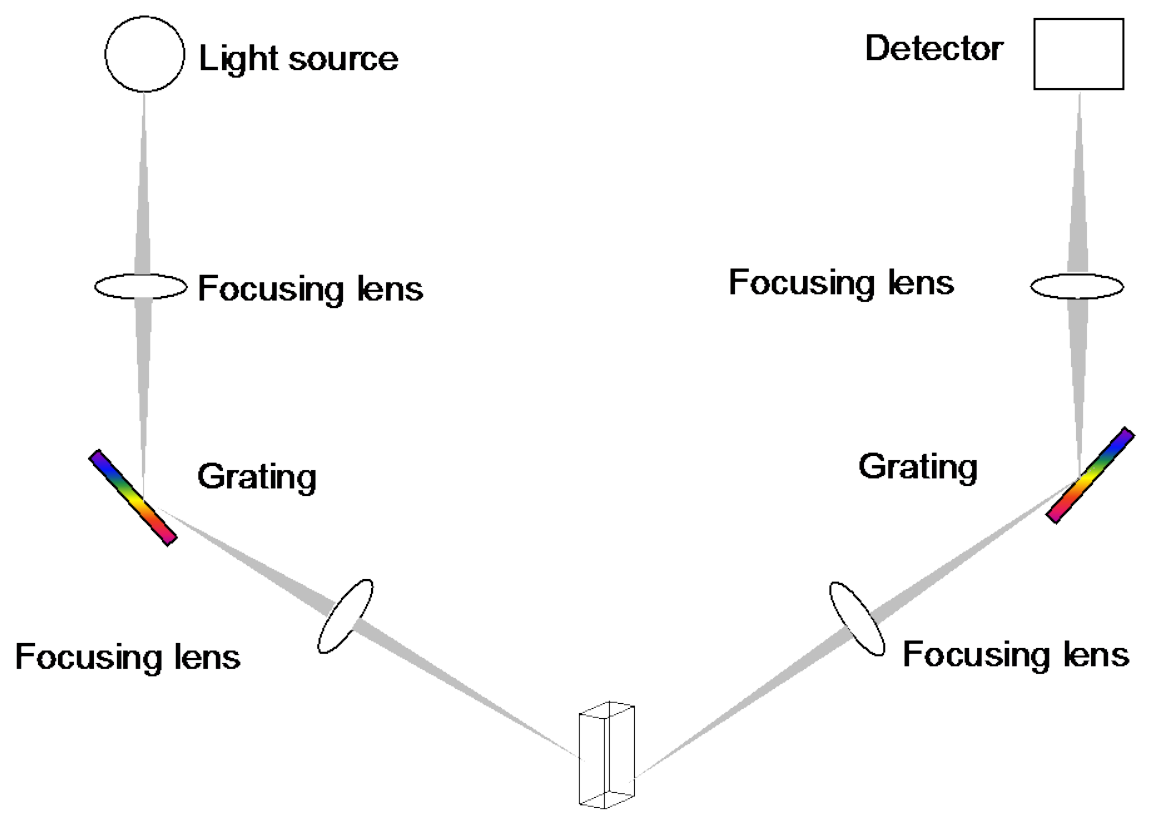

Sample cell

Figure 1b). 


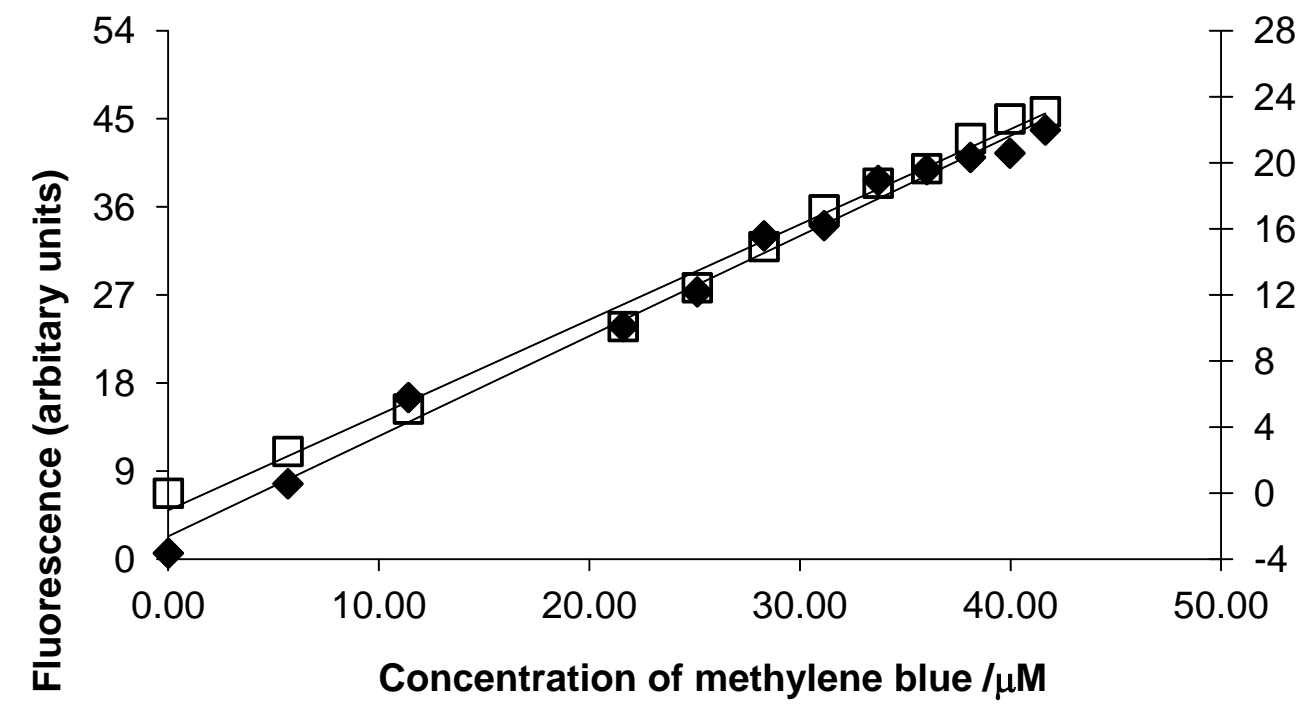

$\diamond$ Bench Fluorometer (left Y-axis) $\square$ Compact Fluorimeter (right Y-axis)

Figure 2.

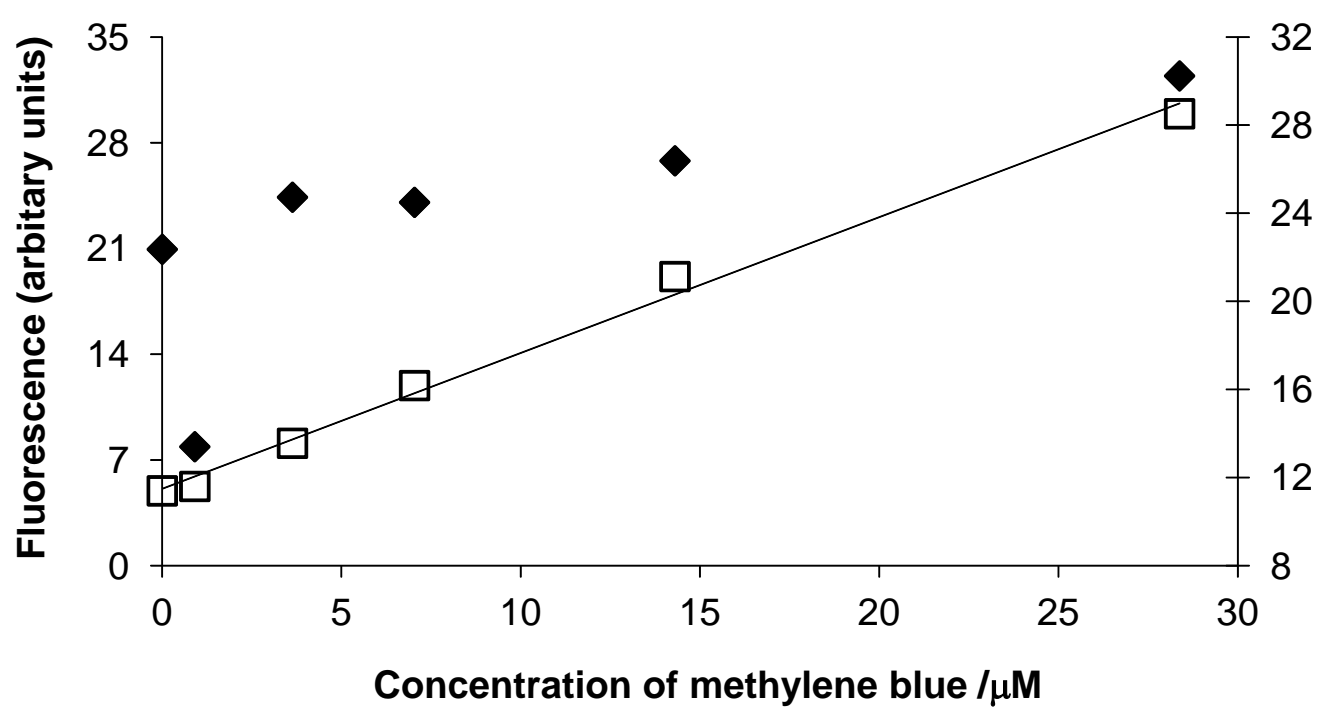

$\bullet$ Bench Fluorometer (left Y-Axis) $\quad$ cCompact Fluorimeter (right Y-axis)

Figure 3. 


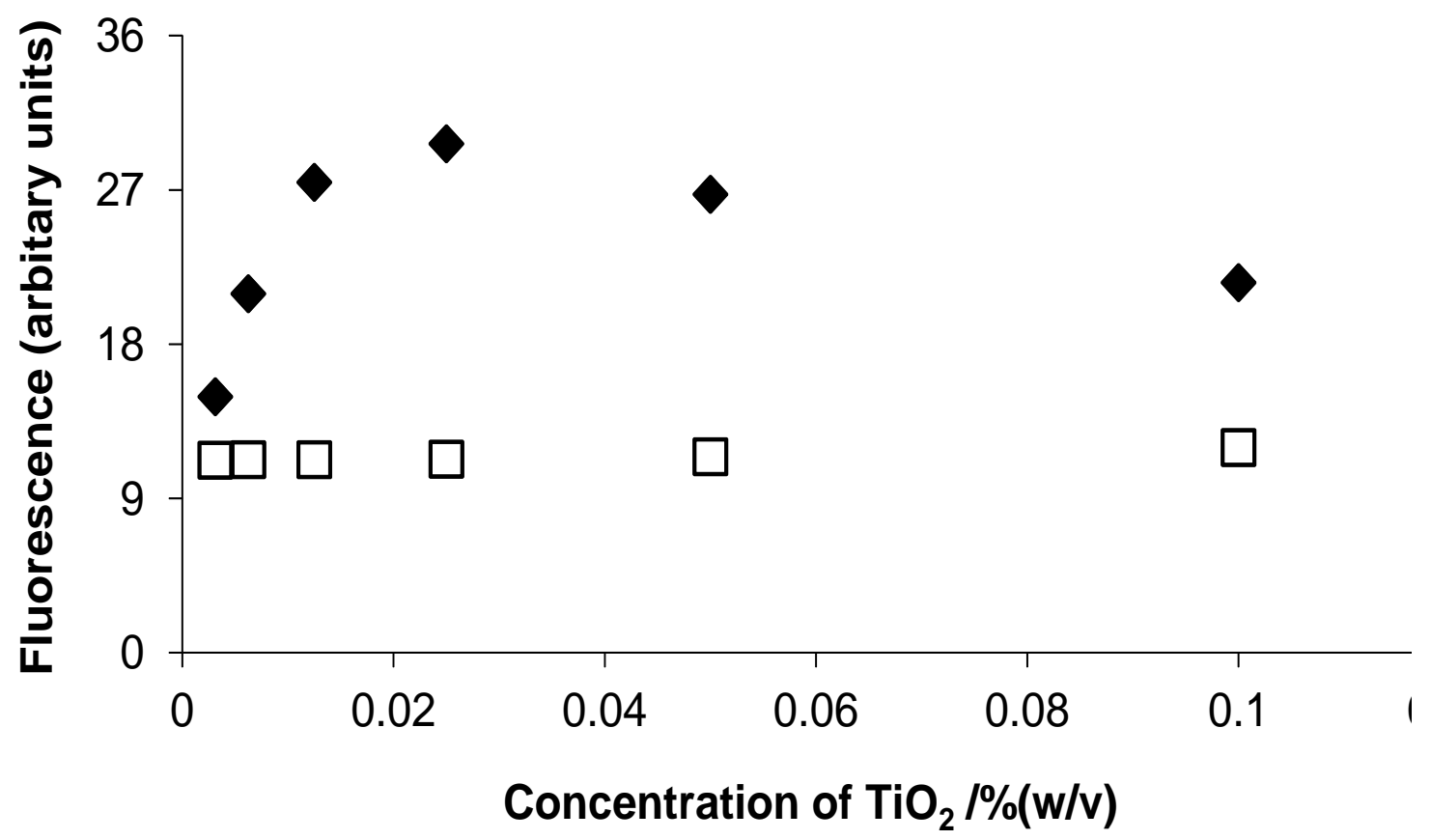

Figure 4. 


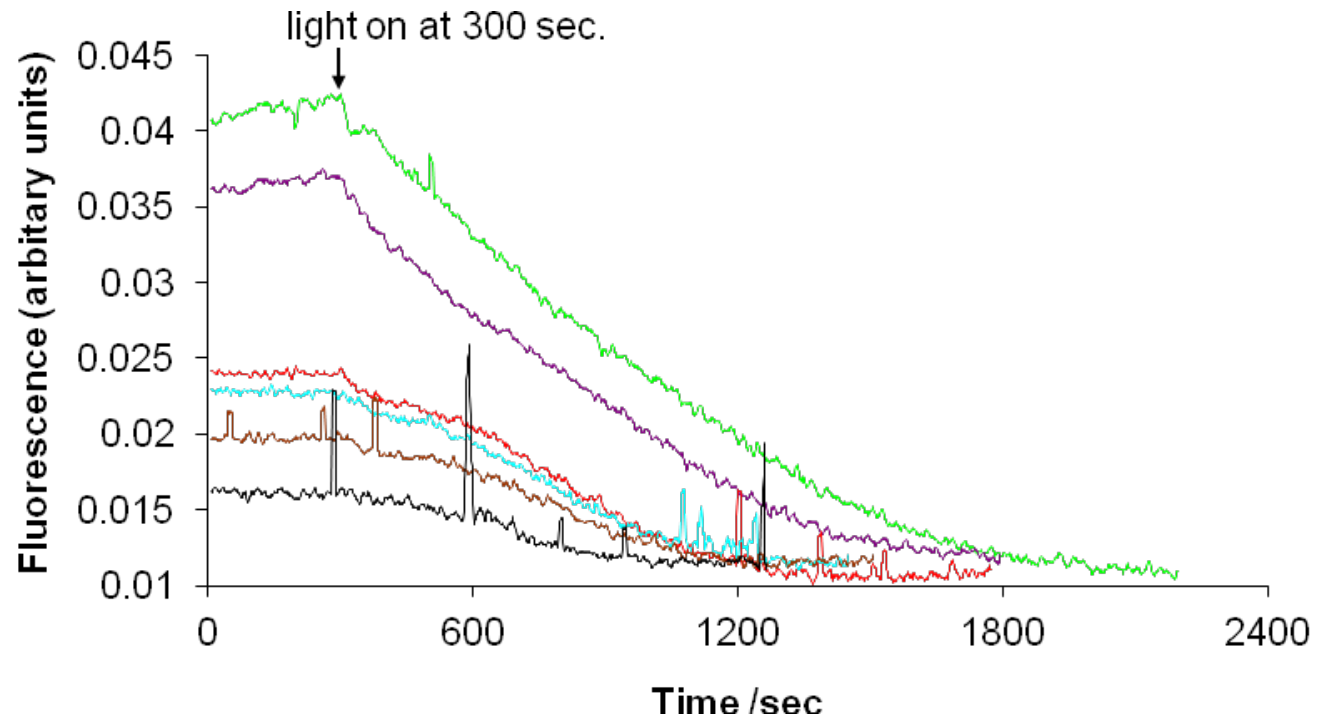

Figure 5. 


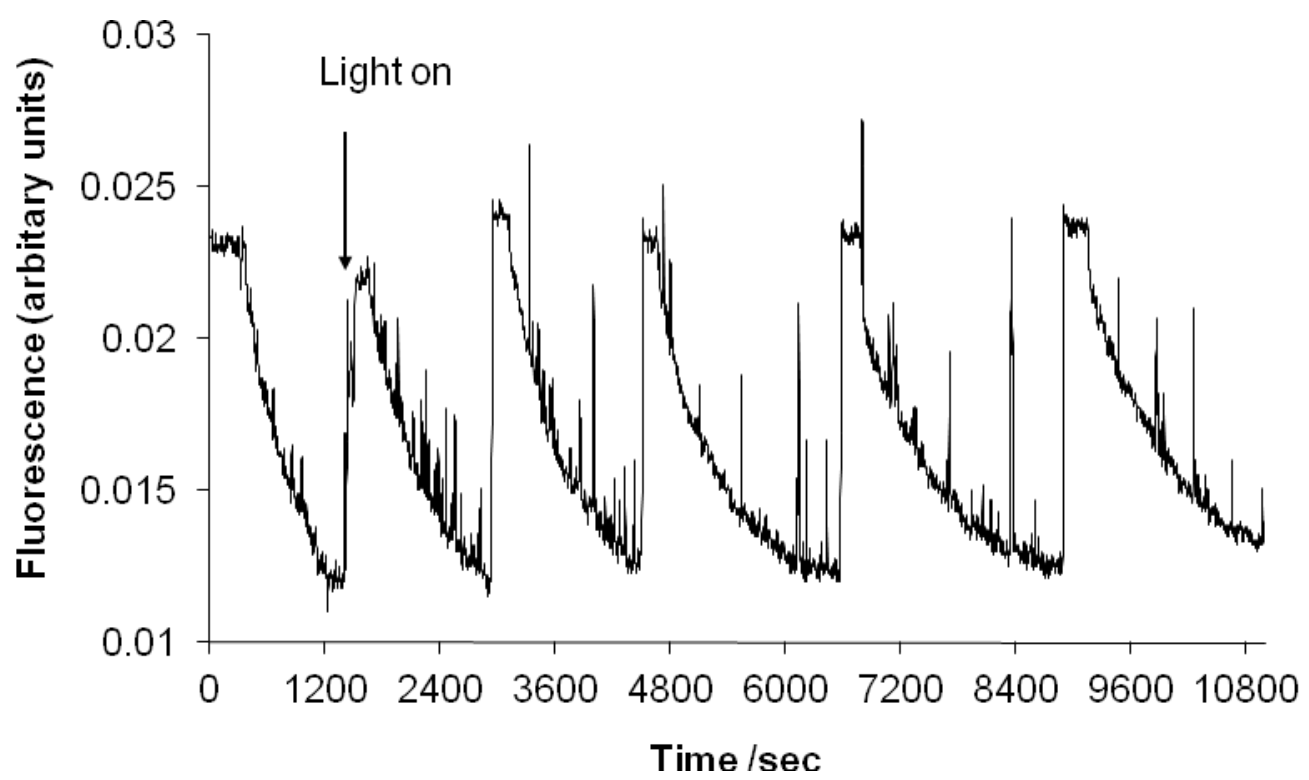

Figure 6. 


\section{Author Biographies}

Professor Peter Robertson BSc. (Hons), D.Phil., C.Chem., C.Sci., FRSC., FICl, C. Eng. FEl..

Professor Peter Robertson originally studied Chemistry and Economics at the University of Ulster, where he also undertook his D.Phil. On completing this Professor Robertson joined the Faraday Centre a spinout company from Carlow Institute of Technology in Ireland. In March 1991 he moved to the Northern Ireland Civil Service as a Higher Scientific Officer and was involved in a range of environmental research projects.

Professor Robertson joined the staff of the School of Applied Sciences at Robert Gordon University in September 1995 where he was involved in teaching and research in environmental science and technology, analytical science and photocatalysis. In July 2000 Professor Robertson was appointed to the Chair of Energy and Environmental Engineering in the School of Mechanical and Offshore Engineering at RGU where he established the multidisciplinary Centre for Research in Energy and the Environment. Professor Robertson subsequently was appointed as Vice-Principal and Pro ViceChancellor (Research and Commercialisation) at Robert Gordon University in September 2006. In this role he is responsible for setting and implementing the Research, Knowledge Transfer and Commercialisation Strategy for the University.

Professor Robertson is a non-executive director of the Aberdeen Renewable Energy Group and the Satrosphere Science Centre. He was a member of the Northern Ireland Water Council (2003-2007), a body advising all departments in the NI Civil Service on the exercise of their functions under Water Legislation. He is also a member of the Universities Scotland Research and Commercialisation Committee. Professor Robertson was also a Royal Society of Edinburgh International Exchange Fellow at the Institute of Chemistry at the Chinese Academy of Science in 2006. Professor Robertson is the Director of Short Term Scientific Missions for European COST Action 540, "PHONASUM-Photocatalytic Technologies and Novel Nanosurfaces Materials" and UK representative to the Management Committee of COST Action 540. He is a member of the editorial board of the International Journal of Photoenergy and Invited Editor of The Handbook of Environmental Chemistry Series Published by Springer Verlag, specifically co-editor of the Volume on Environmental Photochemistry. Professor Robertson's research interests ifocus on advanced oxidation technologies for water treatment, specifically by-products generated by the offshore oil and gas industry and toxic compounds in drinking water. The other main area of his research is in the development of sensor technologies to support the off-shore oil and gas industry. He has been involved in the development of in-situ multicapability array sensors for monitoring hydrocarbon, synthetic based fluid and heavy metal pollution in the marine environment. $\mathrm{He}$ has over 130 publications in the areas of semiconductor photocatalysis, environmental technology and in-situ sensing. 


\section{Professor Daniel McStay, BSc. PhD, C.Phys. FIOP.}

Professor Daniel McStay obtained a BSc in Physics from the University of Stracthclyde, Scotland, U.K. He has over 25 years of experience in developing sensors and instrumentation, primarily optoelectronic based systems. His previous experience includes time as a Professor of Optoelectronics and positions as Chief Scientific Officer and director of technology based companies, as well as a variety of consultancy positions. He has worked with FMC Technologies since 2005 as a specialist Optoelectronics consultant tasked with developing the company's optoelectronics technology strategy and assisting in establishing a subsea optoelectronics research capability within the company. He is a visiting Professor at the Italian National agency for new technologies, Energy and sustainable economic development.

\section{Professor Pat Pollard, BSc, PhD, CChem, MRSC, AMIEEE}

Professor Pat Pollard is Director of the Robert Gordon University, Centre for Research in Energy and the Environment $(\mathrm{CRE}+\mathrm{E})$ a multidisciplinary research centre and has 30 years of experience in applied research in environmental monitoring, the development of real time and in-situ measurement technologies, and the development of tracers and taggants. She has also been part of research into improved sampling regimes adopted by the UKNMP (UK National Marine monitoring programme) and the European Marine Monitoring Programme. Although quite a lot of her research has been confidential she also has a large body of published work and holds several patents. She is a reviewer for several scientific journals including The Analyst and the Journal of Fluorescence and has strong links with industry and other end users.

\section{Dr Soo-Keun Lee.}

Soo-Keun Lee is a principal researcher of division of nano/bio technology at Daegu Gyeongbuk institute of Science and Technology(DGIST) in Korea. Dr. Lee received his Ph.D. in applied sciences from Robert Gordon University(UK) in 2001, worked as a research fellow and professor at the University of Strathclyde(UK) and POSTCH(Korea). $\mathrm{He}$ joined the DGIST in 2005. He is a multidisciplinary scientist with research interests in sensor development, environmental photocatalysis (nano-crystalline titania) and optoelectronics. 